\title{
A Straightforward Route to Enantiopure Pyrrolizidines and Indolizidines by Cycloaddition to Pyrroline $N$-Oxides Derived from the Chiral Pool*
}

\author{
Andrea Goti,** Stefano Cicchi, Franca M. Cordero, Valentina Fedi and Alberto Brandi** \\ Centro di Studio C.N.R. sulla Chimica e la Struttura dei Composti Eterociclici e loro Applicazioni \\ (CSCEA), Dipartimento di Chimica organica "Ugo Schiff", Università di Firenze, via G. Capponi 9, I- \\ 50121 Firenze, Italy. Tel. +39 55 2757610, Fax +39 055 2476964, Email goti@ chimorg.unifi.it
}

* Part of this work was presented at ECSOC-1, http://www.mdpi.org/ecsoc-1.htm (A0014), 1-30 September 1997.

** Author to whom correspondence should be addressed.

Received: 29 October 1997 / Accepted: 30 March 1998 / Published: 22 December 1998

\begin{abstract}
Enantiomerically pure, five membered cyclic nitrones, easily obtained in large amounts from protected hydroxyacids and aminoacids such as D- and L-tartaric, L-malic, and L-aspartic acids, give cycloaddition reactions with a good diastereocontrol. The adducts of L-malic and L-aspartic acids derived from addition of nitrones to dimethyl maleate and $\gamma$ crotonolactone were easily converted into enantiopure pyrrolizidinones, which can be transformed into polyhydroxypyrrolidines or polyhydroxypyrrolizidines, both interesting compounds as potential glycosidase inhibitors. The method is suitable for natural products synthesis as exemplified by a straightforward and convenient access to the pyrrolizidine alkaloid necine base (-)-hastanecine, as well as to indolizidine alkaloids, i.e. (+)lentiginosine.
\end{abstract}

Keywords: Pyrrolizidines, pyrrolidines, stereoselective cycloaddition, glycosidase inhibitors, cyclic nitrones, review

\section{Introduction}

Nitrones have been recently the subject of intense research efforts, because of the wide role played in the synthesis of complex molecular frameworks. They display reactivity either as 1,3-dipoles in

(C) 1999 MDPI. All rights reserved. 
cycloaddition reactions towards structurally differentiated dipolarophiles [1] as well as electrophiles towards attacking organometal counterparts [2]. Both the reactions give rise to the formation of new carbon-carbon bonds, often with a high degree of stereocontrol. These features, together with the direct access to nitrones by simple reactions [1d,3], and their stability which permits isolation and long storage, make nitrones ideal tools for application in organic syntheses, particularly in the field of alkaloids, nitrogen containing natural products or bioactive analogs [1-4].

Recent years have witnessed a renewed interest in this chemistry, mainly due to the development of methods for the preparation of enantiomerically pure nitrones and their subsequent application in synthesis. In this context, enantiopure cyclic nitrones have proved particularly useful [5]. This account summarizes our own achievements in this field.

\section{Results}

Nitrones 1 (and the corresponding enantiomers) are easily available in multi-gram quantities by means of two alternative strategies (a or b, Scheme 1) from inexpensive L- (or D-) tartaric acid [6,2i], available in bulk. The choice of route $\mathbf{a}$ or $\mathbf{b}$ for accessing the target nitrones $\mathbf{1}$ depends on the desired protective groups to be placed at the hydroxyl functionalities. When protective groups allow the use of route a, consisting of protection at the stage of the tartaric esters, followed by reduction, tosylation and ring-closure with hydroxylamine, it gives a more reliable, reproducible and high-yielding pathway [6a]. The synthesis of silylated nitrones 1 cannot be carried out by route a due to scrambling of silicon at the reduction step. The synthesis of TBDPS and TBDMS protected $\mathbf{1}$ was achieved by route $\mathbf{b}$, which requires initial cyclization to a pyrrolindione and subsequent reduction and protection [6b,c].

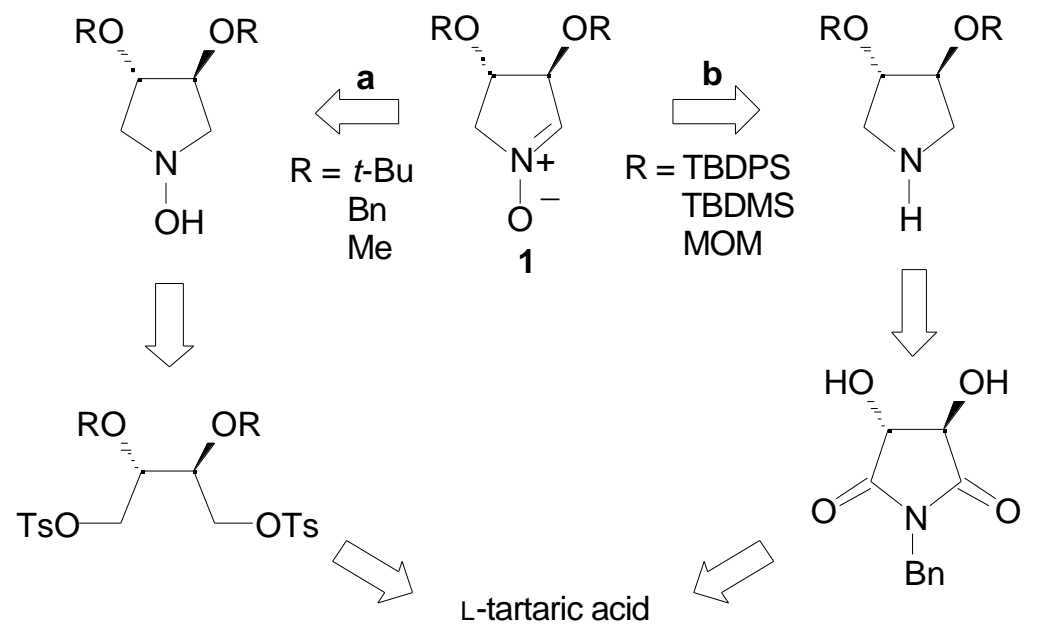

Scheme 1. Retrosynthetic schemes for tartaric acid derived nitrones $\mathbf{1 .}$

Nitrones 1 have been successfully applied to straightforward syntheses of polyhydroxyindolizidines, compounds that have been recently recognized as glycosidase inhibitors and important pharmacological tools [7]. The synthesis of the naturally occurring alkaloid (+)-lentiginosine (4) [8], a potent inhibitor of amyloglucosidases [8-10] serves to illustrate the potentialities of enantiopure nitrones $\mathbf{1}$. The first synthesis of the pure natural compound $[11,9]$ has been attained by a 
sequential methylenecyclopropane (2) cycloaddition to the nitrone 1a followed by thermal rearrangement to the indolizidinone $\mathbf{3}$ (Scheme 2), according to a general methodology developed in our group [12]. The ketone $\mathbf{3}$ provided the desired alkaloid $\mathbf{4}$ by the Caglioti reduction and deprotection $[9,11]$.

An alternate route consisting of cycloaddition of nitrone $\mathbf{1 b}$ to butenol (5) was able to furnish (+)lentiginosine (4) with an overall yield increased of an order of magnitude (25\% vs. 2.4\%) [13]. Elaboration of the adduct $\mathbf{6}$ according to Tufariello [4b,14] gave the diprotected triol 7, which eventually furnished the alkaloid $\mathbf{4}$ by radical deoxygenation and deprotection (Scheme 2). Both procedures also allowed access to 7-hydroxylentiginosines $\mathbf{8}$ and $\mathbf{9}$ by appropriate elaboration of $\mathbf{3}$ and 7, respectively (Scheme 3) [13,6c].

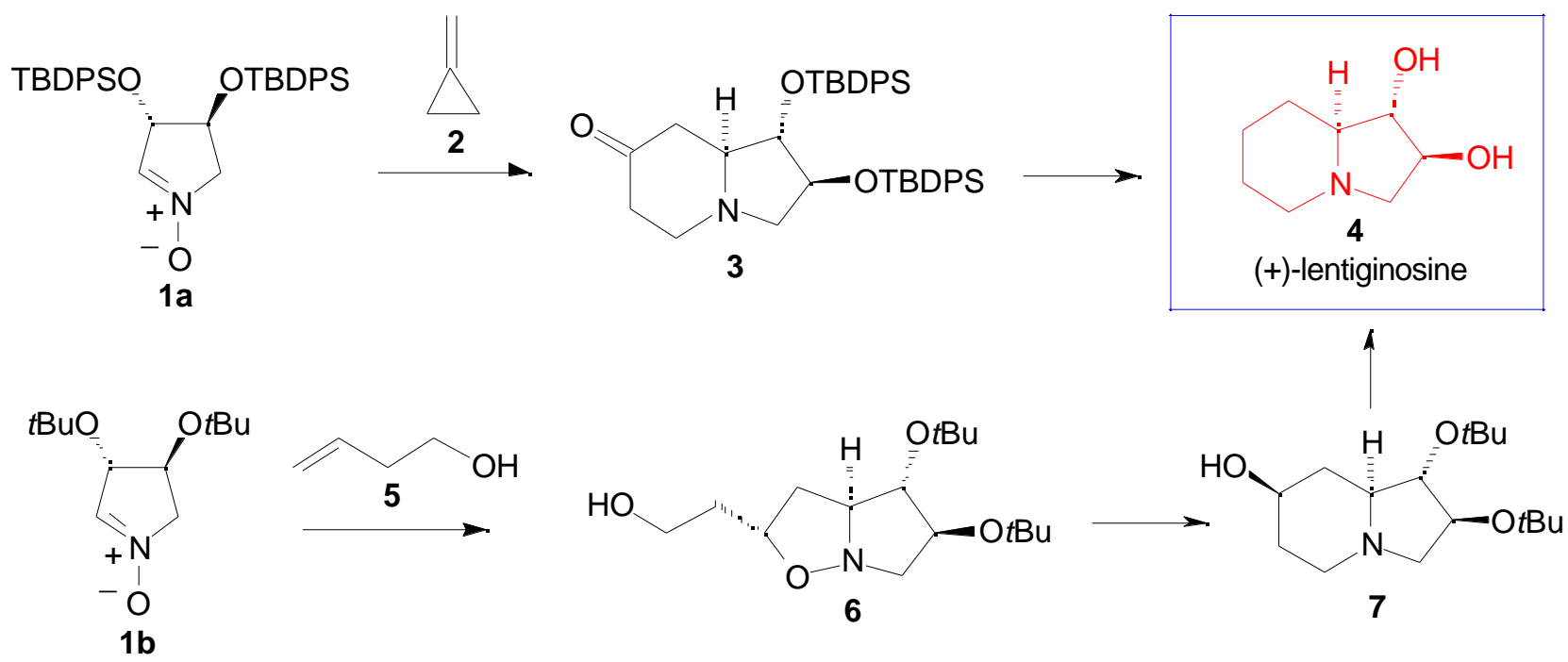

Scheme 2. Syntheses of (+)-lentiginosine by cycloaddition to nitrones $\mathbf{1}$.

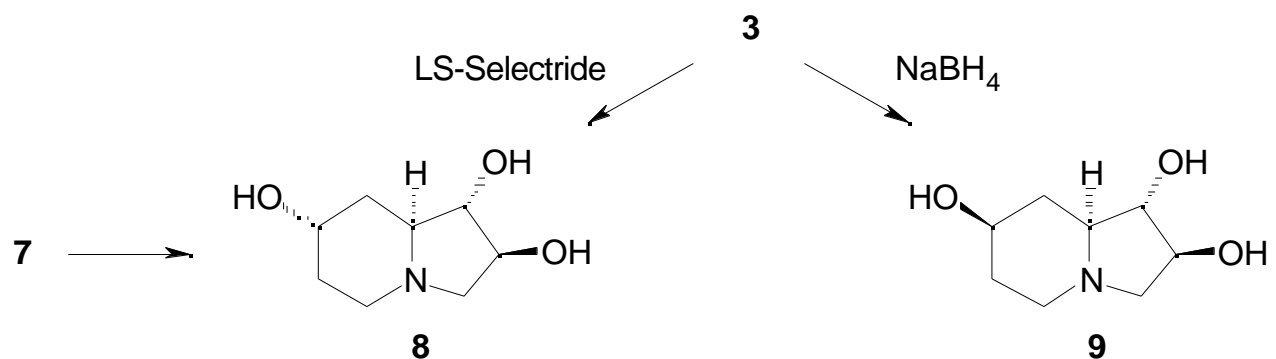

Scheme 3. Synthesis of 7-hydroxylentiginosines.

Our attention was then turned to the synthesis of protected monohydroxy substituted pyrroline $N$ oxides. An additional synthetic problem due to the non symmetric nature of the nitrone precursor arose in this case, whichever strategy, a or $\mathbf{b}$, we chose. Regioisomeric mixtures of nitrones, consequently, have to be expected in the final oxidation step. However, when procedure a was applied to the 
synthesis of a tert-butyl protected nitrone $\mathbf{1 2}$ from -malic acid, a rewarding 9:1 ratio of the desired nitrone 12 vs. its regioisomer 13 was obtained (Scheme 4) [15].

In order to determine the structural factors required to afford synthetically useful regioselection, a study of the effect of substituents at the 3-position of hydroxypyrrolidine has been considered. The results of yellow mercuric oxide oxidation of alkyl, phenyl, nitrogen and oxygen substituted hydroxylamines $\mathbf{1 4}$ are reported in Table 1[16].

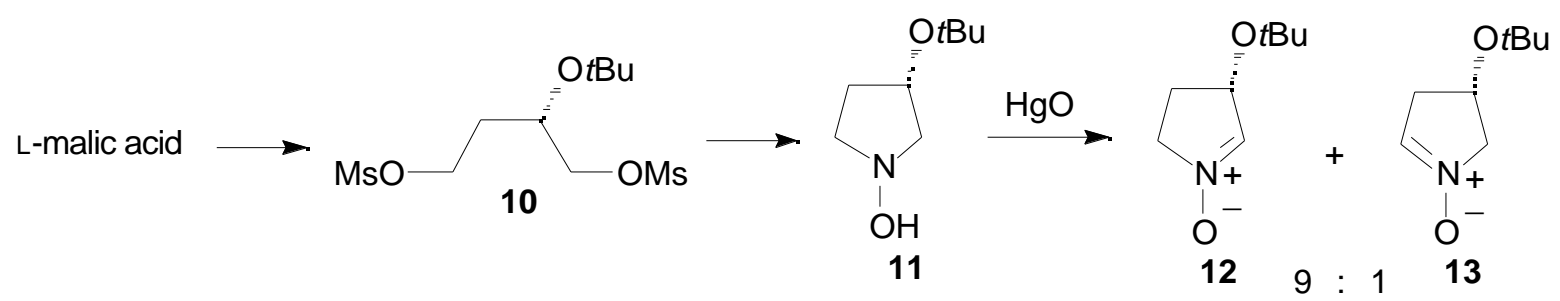

Scheme 4. Synthesis of nitrone 12.

Table 1. Ratios of regioisomeric nitrones $\mathbf{1 5}$ and $\mathbf{1 6}$ from $\mathrm{HgO}$ oxidation of hydroxylamines $\mathbf{1 4}$.

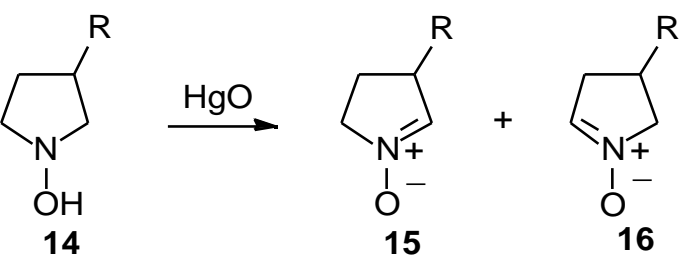

\begin{tabular}{ccc}
\hline $\mathrm{R}$ & $\begin{array}{c}\text { Regioisomeric } \\
\text { Ratio }\end{array}$ & $\begin{array}{c}\text { Yield } \\
(\%)\end{array}$ \\
\hline $\mathrm{Me}$ & 1.8 & 90 \\
$\mathrm{Ph}$ & 2 & 95 \\
$(S)-\mathrm{NBn}{ }_{2}$ & 4 & 12 \\
$(S)-\mathrm{OH}$ & 5 & 24 \\
$(S)-\mathrm{O} t \mathrm{Bu}$ & 9 & 80 \\
$(S)-\mathrm{OAllyl}$ & 9 & 100 \\
$(S)-\mathrm{OTBDMS}$ & 12 & 64 \\
$(S)-\mathrm{OCOPh}$ & $>20$ & 50 \\
& & \\
\hline
\end{tabular}


In all cases a preference for oxidation at the position vicinal to the substituent to afford compound 15 has been found. The amount of this regioisomer increased consistantly with the ability of the substituent to stabilize a negative charge. This effect was rationalized on the basis of the stabilizing stereoelectronic effect provided by an adjacent electronegative group in the TS of the rate-determining step of the oxidation. According to the hypothesized mechanism, in fact, the intermediate nitrosonium cation 17, formed in the first step, requires the removal of a proton to go to the final nitrone, as indicated in Figure 1[15,16]. Similar selectivity ratios were obtained with different oxidants, such as TPAP/NMO [17], $\mathrm{Cu}^{\mathrm{II}} / \mathrm{O}_{2}$, DDQ, while more complex mixtures and low yields were produced by MCPBA oxidation [15]. A lower regioselectivity (6.8:1) has been reported for the synthesis of tertbutyldimethylsilyl substituted nitrones $\mathbf{1 5}$ and $\mathbf{1 6}$ by direct oxidation of the corresponding pyrrolidine with $\mathrm{Na}_{2} \mathrm{WO}_{4} / \mathrm{H}_{2} \mathrm{O}_{2}$ [18].

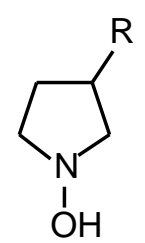

14

(1)

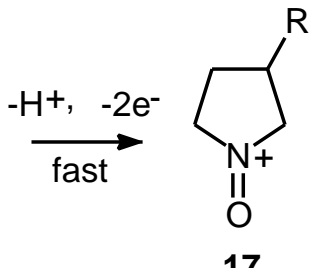

17

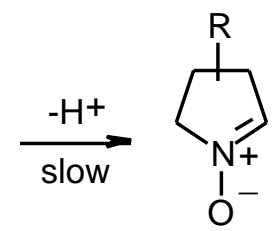

15 and 16

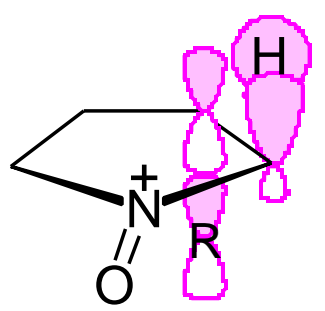

Figure 1. Mechanism proposed for the oxidation of $N$-hydroxypyrrolidines and representation of the orbital interaction which justifies the observed regioselectivity.

Support to both the above mechanism and soundness of the proposed $\sigma_{\mathrm{C}-\mathrm{H}} \rightarrow \sigma^{*}{ }_{\mathrm{C}-\mathrm{R}}$ interaction, which implies the anti proton to be selectively removed, was derived from a labeling study of nitrone 12. Deuteration of $\mathbf{1 2}$ by reduction with LiAlD $_{4}$ gave the hydroxylamine $\mathbf{1 8}$ with complete stereoselectivity. Oxidation of 18 with $\mathrm{HgO}$ gave back nitrone 12 together with its deuterated regioisomer 19 (Scheme 5) [15]. Two relevant findings of the process are consistent with the proposed mechanism: i) nitrone 12 obtained from 18 contained no deuterium, that means the hydrogen (deuterium) anti to $t$-BuO is removed selectively; ii) the regioselectivity decreased to $2: 1$, which implies a strong primary kinetic isotopic effect $\left(\mathrm{k}_{\mathrm{H}} / \mathrm{k}_{\mathrm{D}} \approx 4.5: 1\right)$, in accord with involvement of the anti proton in the rate-determining step of the process. 


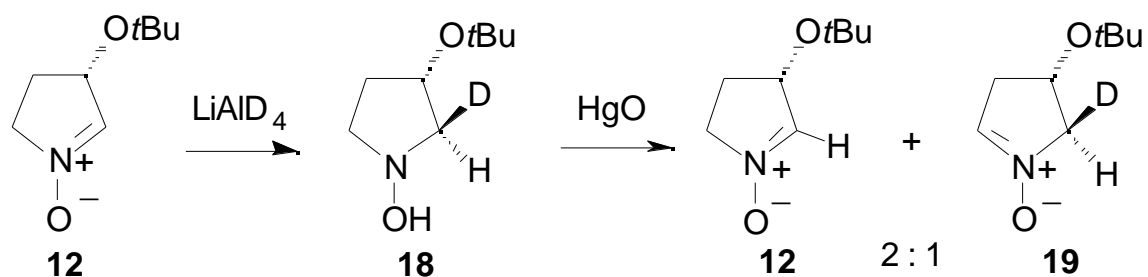

Scheme 5. Oxidation of deuterated hydroxypyrrolidine 18.

From a synthetic point of view, the fact that all the oxygen-substituted derivatives gave significantly high regioselectivity was of particular interest. Specifically, the total selectivity attained for formation of ester-substituted nitrones might be very useful synthetically. Preparation of nitrogen-substituted nitrones was more ineffective due to a lower regioselectivity in the oxidation, and especially to low yields in the overall process, ascribed to competing reactions connected with the higher nucleophilicity of nitrogen. Another method was then devised, which furnished nitrone $\mathbf{2 3}$ more effectively and with complete selectivity. The one-pot mono-mesylation of diol 20, followed by Swern oxidation and condensation of the aldehyde $\mathbf{2 2}$ with hydroxylamine gave the nitrone $\mathbf{2 3}$ directly, isolated in $24 \%$ overall yield (Scheme 6) [16].

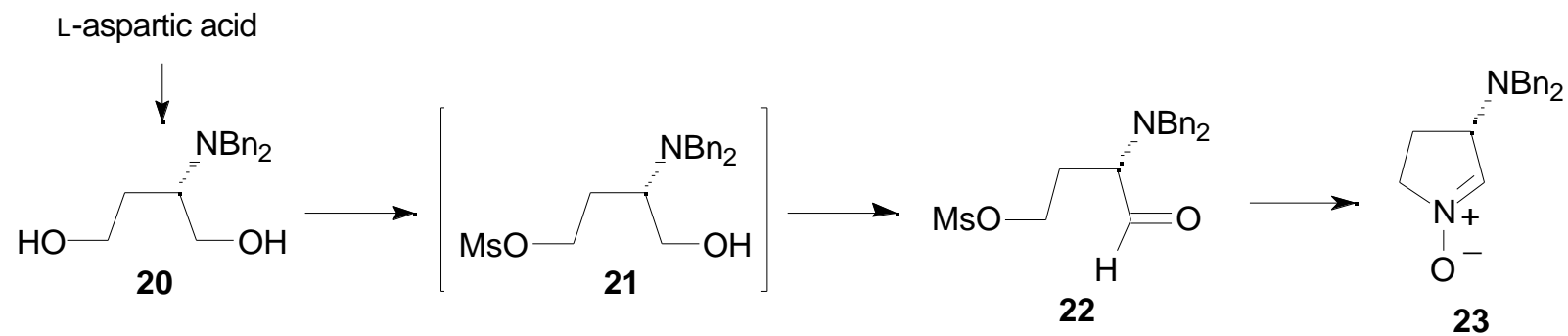

Scheme 6. Selective synthesis of nitrone 23.

The enantiomerically pure nitrones $\mathbf{1 2}$ and $\mathbf{2 3}$ were then reacted with the appropriate ester substituted ethylenic compounds, i.e. dimethyl maleate and $\gamma$-crotonolactone, for the purpose of synthesizing enantiopure pyrrolizidines, pyrrolidines and structurally related compounds according to the general process represented in Scheme 7 [19].
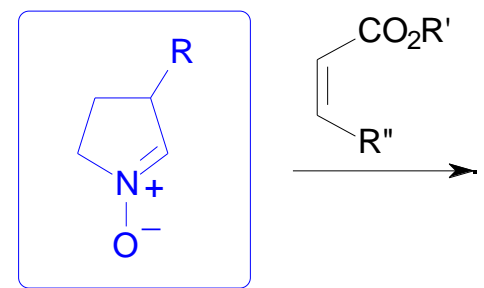<smiles>[R]C1CCN2OC([R])C(C(=O)O)C12</smiles>
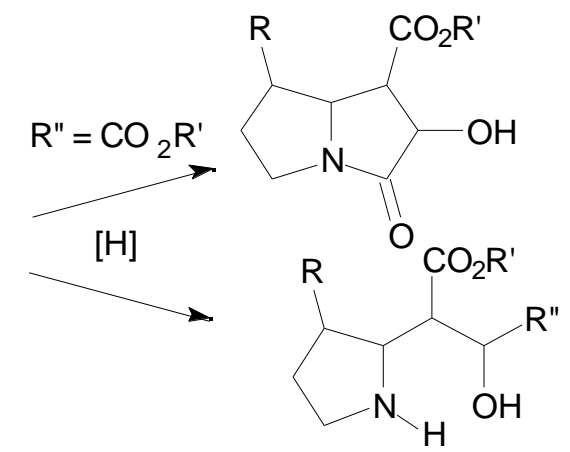

Scheme 7. General strategy for the synthesis of enantiopure pyrrolizidines from nitrones $\mathbf{1 2}$ and $\mathbf{2 3}$. 
The 1,3-dipolar cycloaddition of nitrone 12 with dimethyl maleate (24) gave three cycloadducts 25a-c in a 5:1:1 ratio (Scheme 8). As expected $[6,9,13,15,16,19]$, the major adduct 25a is derived from the less encumbered exo-anti TS. The minor adducts $\mathbf{2 5 b}$ and $\mathbf{2 5 c}$ arose from roughly equi-energetic endo-anti and exo-syn TS, respectively, while formation of the fourth possible adduct was prevented by the sterically unfavored endo-syn approach (Figure 2) [20].

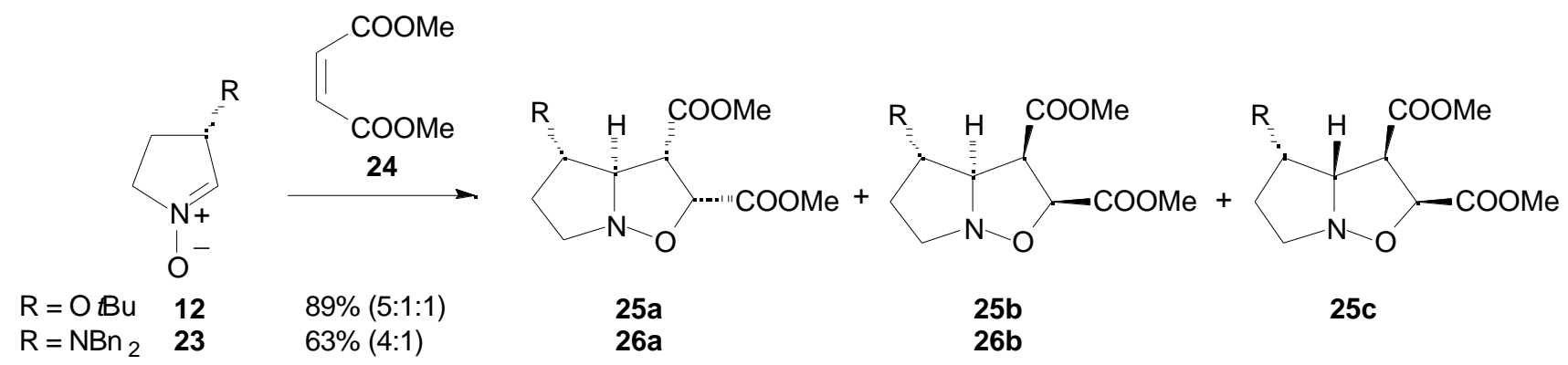

Scheme 8. Cycloadditions of nitrones $\mathbf{1 2}$ and $\mathbf{2 3}$ to dimethyl maleate (24).

The analogous cycloaddition of nitrone $\mathbf{2 3}$ to $\mathbf{2 4}$ gave only two adducts $\mathbf{2 6 a - b}$ in 4:1 ratio (Scheme 8). The dibenzylamino group, more sterically demanding than the tert-butoxy one, can account for the absence of products derived from the sterically more hindered syn approaches (Figure 2).
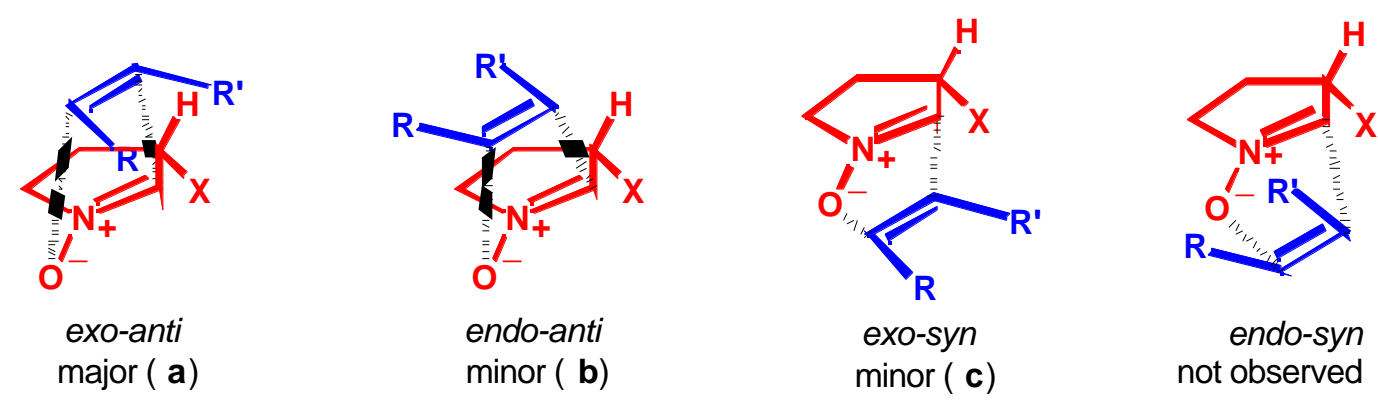

Figure 2. Possible approaches of 3-substituted pyrroline $N$-oxides to $Z$-disubstituted ethylenes.

$\gamma$-Crotonolactone (27) is another suitable dipolarophile for synthesizing the pyrrolizidine target compounds [21]. Indeed, 27 and butenolides in general are known to give an unique regioisomer [21,22], with a better exo/endo selectivity than maleic acid derivatives in cycloadditions to cyclic nitrones [21,22a], probably due to the loss of the favorable secondary orbital interactions in the TS. Accordingly, the reaction of nitrone 12 with 27 gave only two adducts 28a and 28c in the same 5:1 ratio (Scheme 9). The compounds are derived from the two possible exo approaches, anti and syn respectively, to the substituent on the nitrone. 


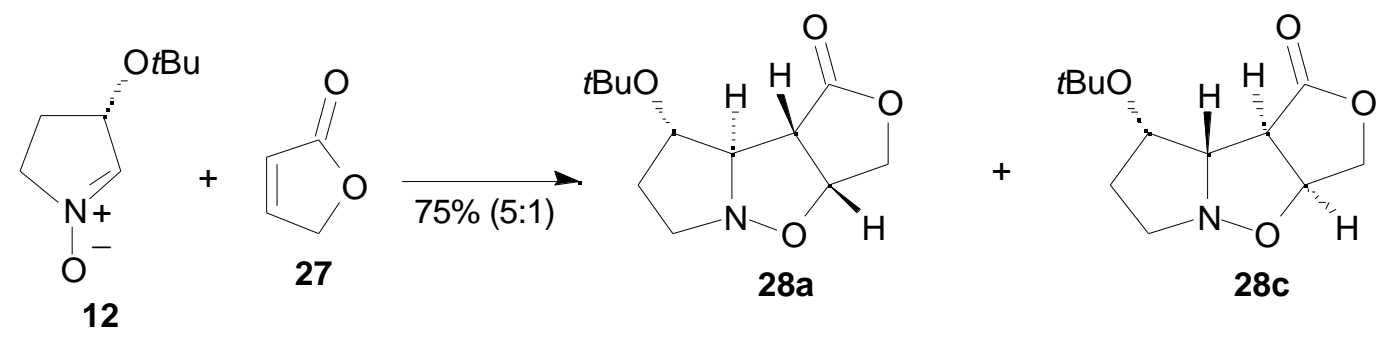

Scheme 9. Cycloaddition of nitrone 12 to $\gamma$-crotonolactone (27).

The transformation of adducts $\mathbf{2 5}$ and $\mathbf{2 6}$ into the desired pyrrolizine skeleton requires a simple opening of the isoxazolidine ring by reductive cleavage of the $\mathrm{N}-\mathrm{O}$ bond, since re-closure to form a lactam moiety by attack of nitrogen to the $\gamma$-carboxylic carbon atom occurs spontaneously [23,21]. A mild method consisting of refluxing the isoxazolidine in aqueous acetonitrile in the presence of molybdenum hexacarbonyl has been recently introduced to perform this transformation [24]. The separated isoxazolidines 25a and 25c gave good to excellent yields of 29a and 29c, respectively, in this step (Scheme 10). The mixture of isoxazolidines $\mathbf{2 6 a - b}$ turned out to be inseparable by flash column chromatography, but when subjected directly to the reductive ring-opening afforded only the pyrrolizidinone 30 (Scheme 10).

tBuO<smiles>COC(=O)[C@H]1ON2CC[C@@H](O)[C@H]2[C@H]1C(=O)O</smiles>

tBuO<smiles>COC(=O)C1ON2CC[C@H](O)[C@H]2C1C(=O)OC</smiles>

$25 \mathrm{c}$<smiles>CC(=O)[C@H]1ON2CC[C@H](Nc3ccccc3)[C@@H]2[C@H]1C(C)=O</smiles>

26a<smiles>CCCCOC1CCN2C(=O)C(O)[C@H](C(C)=O)[C@H]12</smiles><smiles>CC(=O)C1[C@H](O)C(=O)N2CC[C@H](OC(C)C)[C@H]12</smiles><smiles>COC(=O)[C@H]1[C@H](O)C(=O)N2CC[C@H](Nc3ccccc3)[C@H]12</smiles>

Scheme 10. Reductive ring-opening-lactamization to pyrrolizidinones 29 and $\mathbf{3 0}$. 
Due to the biological relevance of polyhydroxypyrrolizidines and pyrrolidines as inhibitors of glycosidases and consequently as potential therapeutic (antibiotic, antiviral, antitumoral) agents [7,25], we pursued the synthesis of such compounds and their structural analogs from the pyrrolizidinone 29a and the cycloadduct 28a (Scheme 11). Reduction of 29a gave the monoprotected pyrrolizidine triol 31, which represents a new, non-natural stereoisomer of the necine bases rosmarinecine and croalbinecine. Reduction of the adduct 28a under the same conditions was not able to accomplish the cleavage of the isoxazolidine ring, giving the pyrrolo[1,2-b]isoxazole derivative $\mathbf{3 2}$ in good yields. This compound is also interesting, representing a structural oxygenated analog of polyhydroxypyrrolizidines. On the other hand, under reflux in THF, the reduction proceeded to give the monoprotected tetrahydroxypyrrolidine $\mathbf{3 3}$, which in turn was deprotected to 34 or cyclized to 31 (Scheme 11).

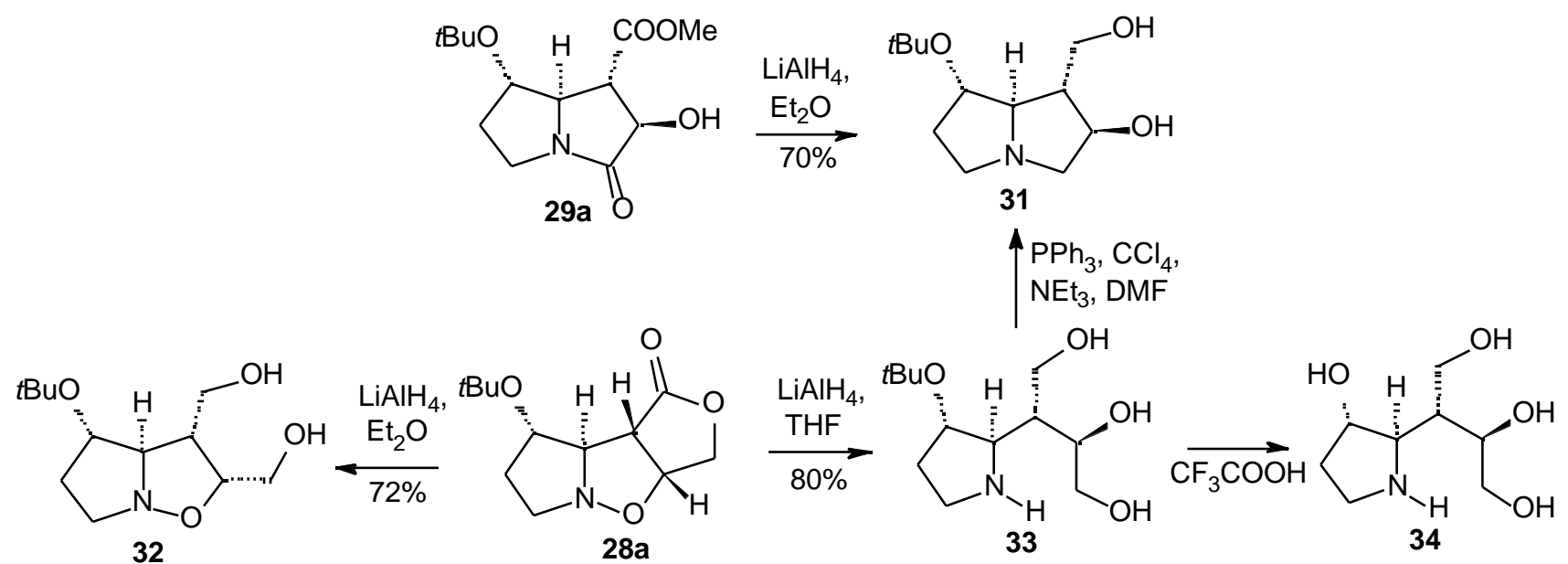

Scheme 11. Elaboration of 28a and 29a to polyhydroxypyrrolidines and pyrrolizidines.
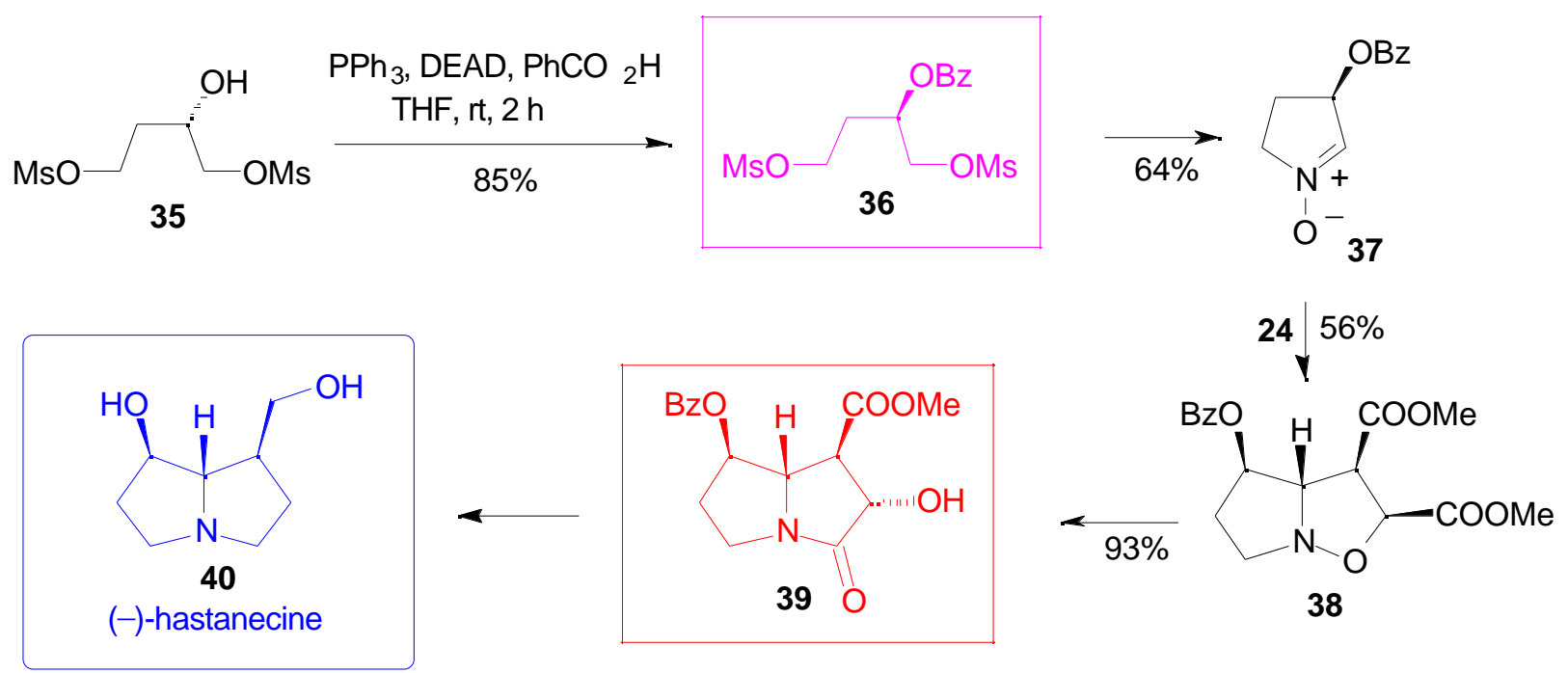

Scheme 12. Synthesis of (-)-hastanecine. 
The whole cycloaddition-lactamization-reduction process outlined in Schemes 8-11 appears flexible enough to warrant its application to the synthesis of natural polyhydroxypyrrolizidines and their bioactive analogs. The formal EPC synthesis of (-)-hastanecine (40) [26], the necine base of several pyrrolizidine alkaloids, starting from nitrone 37 (Scheme 12) is illustrative of this strategy. The configuration of the nitrone to be employed for the synthesis of (-)-hastanecine (as well as for the synthesis of most of the naturally occurring polyhydroxypyrrolizidines) required an inversion of configuration of the stereogenic center of L-malic acid. It is noteworthy that this could be accomplished by a Mitsunobu reaction on dimesylate 35, rather than by use of the more expensive Dmalic acid; in this way, inversion and protection of the hydroxy group occur in the same step. The pyrrolizidinone 39, precursor of the desired (-)-hastanecine (40) [27], was synthesized in only 4 steps and in high yield from the dimesylate 35 [26].

\section{Conclusion}

In conclusion, a straightforward and versatile access to enantiomerically pure polyhydroxypyrrolizidines, pyrrolidines and structural analogs has been outlined. Fundamental for the synthetic strategy is the easy access to variously substituted enantiomerically pure pyrroline $N$-oxides available in a direct and economical manner from the "chiral pool". The potential of the process for the synthesis of pyrrolizidine and indolizidine alkaloids has already been demonstrated. Further application of related procedures to the synthesis of natural products and biologically interesting compounds is underway in our laboratories, as well as biological screening of the products against a variety of glycosidic enzymes.

\section{References and Notes}

1. (a) Tufariello, J. J. In "1,3-Dipolar Cycloaddition Chemistry", Padwa, A.; Ed.; John Wiley \& Sons: New York, 1984.

(b) Confalone, P. N.; Huie, E. M. Org. React. 1988, 36, 1-173.

(c) Torssell, K. B. G. "Nitrile Oxides, Nitrones, and Nitronates in Organic Synthesis"; Feuer, H., Ed.; VCH Publishers: New York, 1988.

(d) Döpp, D.; Döpp, H. In "Houben-Weyl - Methoden der organischen Chemie", vol. E14b, Klamann, D.; Hagemann, H.; Eds.; Georg Thieme Verlag: Stuttgart, 1990.

(e) Breuer, E. In "The Chemistry of Amino, Nitroso and Nitro Compounds and Their Derivatives", Patai, S.; Ed.; Wiley Interscience: New York, 1982.

(f) Frederickson, M. Tetrahedron 1997, 53, 403-425.

2. (a) Enders, D.; Reinhold, U. Tetrahedron: Asymmetry 1997, 8, 1895-1946; and references cited therein.

(b) Dondoni, A.; Junquera, F.; Merchán, F. L.; Merino, P., Scherrmann, M.-C.; Tejero, T. J. Org. Chem. 1997, 62, 5484-5496.

(c) Dondoni, A.; Franco, S.; Junquera, F.; Merchán, F. L.; Merino, P., Tejero, T.; Bertolasi, V. Chem. Eur. J. 1995, 1, 505-520.

(d) Merino, P.; Lanaspa, A.; Merchán, F. L.; Tejero, T. Tetrahedron: Asymmetry 1997, 8, 23812401. 
(e) Merino, P.; Franco, S.; Merchán, F. L.; Tejero, T. Tetrahedron: Asymmetry 1997, 8, 34893496.

(f) Degiorgis, F.; Lombardo, M.; Trombini, C. Synthesis 1997, 1243-1245.

(g) Mancini, F.; Piazza, M. G. Trombini, C. J. Org. Chem. 1991, 56, 4246-4252.

(h) Giovannini, R.; Marcantoni, E.; Petrini, M. J. Org. Chem. 1995, 60, 5706-5707.

(i) Ballini, R.; Marcantoni, E.; Petrini, M. J. Org. Chem. 1992, 57, 1316-1318.

3. Hamer, J.; Macaluso, A. Chem. Rev. 1964, 64, 473-495.

4. (a) Desimoni, G.; Tacconi, G.; Barco, A; Pollini, G. P. "Natural Products Synthesis Through Pericyclic Reactions"; ACS Monograph n. 180; Caserio, M. C., Ed.; American Chemical Society: Washington, 1983.

(b) Tufariello, J. J. Acc. Chem. Res. 1979, 12, 396-403.

5. For some recent examples on the synthesis and use of different chiral, enantiomerically pure, endocyclic nitrones, see:

(a) Golik, J.; Wong, H.; Krishnan, B.; Vyas, D. M.; Doyle, T. W. Tetrahedron Lett. 1991, 32, 1851-1854.

(b) Tronchet, J. M. J.; Zosimo-Landolfo, G.; Balkadjian, M.; Ricca, A.; Zsély, M.; Barbalat-Rey, F.; Cabrini, D.; Lichtle, P.; Geoffroy, M. Tetrahedron Lett. 1991, 32, 4129-4132.

(c) Grigg, R.; Markandu, J.; Perrior, T.; Surendrakumar, S.; Warnock, W. J. Tetrahedron 1992, 48, 6929-6952.

(d) Herczegh, P.; Kovács, I.; Szilágyi, L.; Varga, T.; Dinya, T.; Sztaricskai, F. Tetrahedron Lett. 1993, 34, 1211-1214.

(e) Berranger, T.; Langlois, Y. J. Org. Chem. 1995, 60, 1720-1726.

(f) de March, P.; Figueredo, M.; Font, J.; Gallagher, T.; Milán, S. J. Chem. Soc., Chem. Commun. 1995, 2097-2098.

(g) van den Broek, L. A. G. M. Tetrahedron 1996, 52, 4467-4478.

(h) Ishikawa, T.; Tajima, Y.; Fukui, M.; Saito, S. Angew. Chem. Int. Ed. Engl. 1996, 35, 18631864.

(i) Tamura, O.; Gotanda, K.; Terashima, R.; Kikuchi, M.; Miyawaki, T.; Sakamoto, M. J. Chem. Soc., Chem. Commun. 1996, 1861-1862.

(j) Hall, A.; Meldrum, K. P.; Therond, P. R.; Wightman, R. H. Synlett 1997, 123-125.

(k) Closa, M.; de March, P.; Figueredo, M.; Font, J. Tetrahedron: Asymmetry 1997, 8, 1031-1037.

(l) Katagiri, N.; Okada, M.; Morishita, Y.; Kaneko, C. Tetrahedron 1997, 53, 5725-5746.

(m) Chackalamannil, S.; Wang, Y. Tetrahedron 1997, 53, 11203-11210.

6. (a) Cicchi, S.; Höld, I.; Brandi, A. J. Org. Chem. 1993, 58, 5274-5275.

(b) Brandi, A.; Cicchi, S.; Goti, A.; Koprowski, A.; Pietrusiewicz, K. M. J. Org. Chem. 1994, 59, 1315-1318.

(c) Goti, A.; Cardona, F.; Brandi, A.; Picasso, S.; Vogel, P. Tetrahedron: Asymmetry 1996, 7, 1659-1674.

7. Reviews:

(a) Elbein, A. D. Ann. Rev. Biochem. 1987, 56, 497-534.

(b) Vogel, P. Chimica Oggi 1992, 10 (August-September), 9-15.

(c) Winchester, B.; Fleet, G. W. J. Glycobiology 1992, 2, 199-210.

(d) Legler, G. Adv. Carbohydr. Chem. Biochem. 1990, 48, 319-384. 
(e) Elbein, A. D.; Molyneux, R. J. In "Alkaloids: Chemical and Biological Perspectives"; Pelletier, S. W., Ed.; Wiley-Interscience: New York, 1987; vol. 5, ch. 1.

(f) Howard, A. S.; Michael, J. P. In "The Alkaloids"; Brossi, A., Ed.; Academic Press: New York, 1986; vol. 28, ch. 3.

(g) Cossy, J.; Vogel, P. In "Studies in Natural Product Chemistry"; Atta-ur-Rahman, Ed.; Elsevier: New York, 1993; vol. 12, p. 275.

8. Isolation: Pastuszak, I.; Molyneux, R. J.; James, L. F.; Elbein, A. D. Biochemistry 1990, 29, 18861891.

9. Brandi, A.; Cicchi, S.; Cordero, F. M.; Frignoli, R.; Goti, A.; Picasso, S.; Vogel, P. J. Org. Chem. 1995, 60, 6806-6812.

10. Cardona, F.; Goti, A.; Brandi, A.; Scarselli, M.; Niccolai, N.; Mangani, S. J. Mol. Model. 1997, 3, 249-260.

11. Cordero, F. M.; Cicchi, S.; Goti, A.; Brandi, A. Tetrahedron Lett. 1994, 35, 949-952.

12. (a) Brandi, A.; Cordero, F. M.; Goti, A.; De Sarlo, F.; Guarna, A. Synlett 1993, 1-8.

(b) Goti, A.; Cordero, F. M.; Brandi, A. Top. Curr. Chem. 1996, 178, 1-97.

13. Goti, A.; Cardona, F.; Brandi, A. Synlett 1996, 761-763.

14. Tufariello, J. J.; Tegeler, J. J. Tetrahedron Lett. 1976, 4037-4040.

15. Cicchi, S.; Goti, A.; Brandi, A. J. Org. Chem. 1995, 60, 4743-4748.

16. Goti, A.; Cicchi, S.; Fedi, V.; Nannelli, L.; Brandi, A.J. Org. Chem. 1997, 62, 3119-3125.

17. Goti, A.; De Sarlo, F.; Romani, M. Tetrahedron Lett. 1994, 35, 6571-6574.

18. Murahashi, S.-I.; Imada, Y.; Ohtake, H. J. Org. Chem. 1994, 59, 6170-6172.

19. For a synthesis of hydroxyindolizidines from nitrone 12, see ref. 15 and:

Mc Caig, A. E.; Wightman, R. H. Tetrahedron Lett. 1993, 34, 3939-3942.

20. Syn and anti refer to the approaches of dipolarophile from the same or the opposite face of the substituent at C-3 of the nitrone, respectively.

21. Tufariello, J. J.; Tette, J. P. J. Org. Chem. 1975, 40, 3866-3869.

22. (a) Cid, P.; de March, P.; Figueredo, M.; Font, J.; Milán, S.; Soria, Á.; Virgili, A. Tetrahedron 1993, 49, 3857-3870.

(b) de Lange, B.; Feringa, B. L. Tetrahedron Lett. 1988, 29, 5317-5320.

(c) Banerji, A.; Basu, S. Tetrahedron 1992, 48, 3335-3344.

(d) Saito, S.; Ishikawa, T.; Kishimoto, N.; Kohara, T.; Moriwake, T. Synlett 1994, 282-284.

23. Huisgen, R.; Hauck, H.; Grashey, R.; Seidl, H. Chem. Ber. 1968, 101, 2568-2584.

24. Cicchi, S.; Goti, A.; Brandi, A.; Guarna, A.; De Sarlo, F. Tetrahedron Lett. 1990, 31, 3351-3354.

25. (a) Hartmann, T.; Witte, L. Chemistry, Biology and Chemoecology of the Pyrrolizidine Alkaloids In Alkaloids: Chemical \& Biological Perspectives; Pelletier, S. W., Ed.; Pergamon: Oxford, 1995; vol. 9, p. 155-233.

(b) Mattocks, A. R. Chemistry and Toxicology of Pyrrolizidine Alkaloids; Academic Press: New York, 1986.

26. Goti, A.; Cicchi, S.; Fedi, V.; Nannelli, L.; Brandi, A. Synlett 1997, 577-579.

27. Denmark, S. E.; Thorarensen, A. J. Org. Chem. 1994, 59, 5672-5680.

Samples Availability: Available from the authors.

(C) 1999 by Molecular Diversity Preservation International (MDPI) 